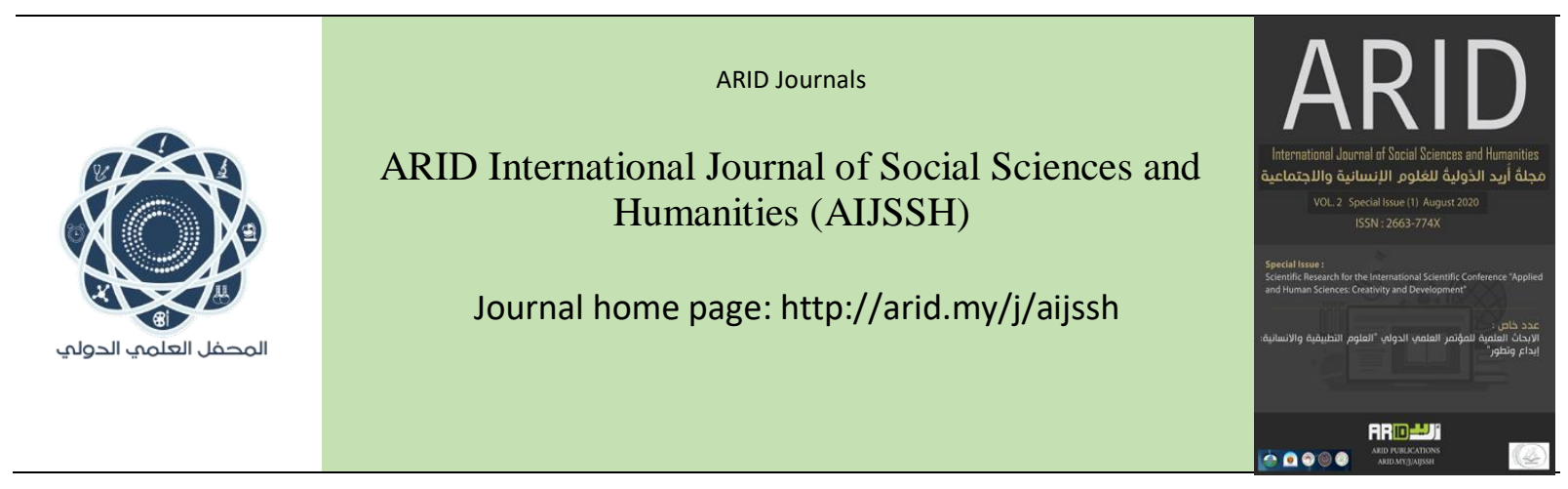

$$
\begin{aligned}
& \text { مَجلةُ أُريد الدَّوليةُ للعُلورج الإنسانية والإجتماعية } \\
& \text { المجلد الثاني ،العدد الخاص ، آب } 2020 \text { م }
\end{aligned}
$$

\title{
Expropriation and Distinguishing it from the Suspected Legal Status
}

\author{
Dr. Ameera Abdul Hussain \\ M. Zainab Jasim Mohammed*
}

م.زينب جاسم محمد*

د.أميرة عبد الحسين

الجامعة العر اقية/كلية القانون و العلوم السياسية/العر اق /بغداد

Zainabjas7979@gmail.com

arid.my/0005-4315

https://doi.org/10.36772/arid.aijssh.2020.s.217 


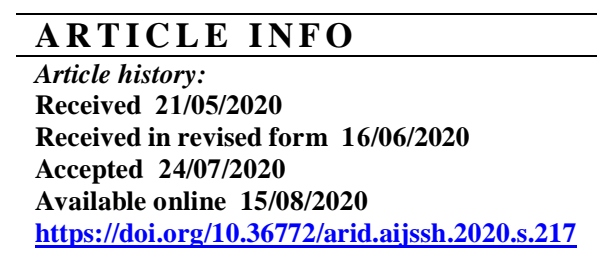

\begin{abstract}
The right of ownership is considered one of the most important original in-kind rights, even the most extensive of which is the oldest of them and that this right entitles its owner to direct authority to use and exploit the property owned and disposed of, therefore this right throughout the ages and times has been guaranteed by constitutions and laws, and was keen to maintain it and made it sacrosanct and prevented infringement, and it has its market The private investment in selling, buying, renting and mortgaging, therefore, modern legislation did not permit the acquisition of real estate or the expropriation of property from its legitimate owner except for the purposes of public benefit exclusively considering that the public benefit is provided for the private benefit because the purpose of the acquisition is to establish service projects and health And its educational and defining types.
\end{abstract}

keywords: Seizure, ownership, compensation, expropriation, legal disposition 


\section{الملخص}

يعتبر حق الملكية من أهم الحقوق العينية الأصلية بل وأوسعها لابل من أقدمها، وأن هذا الحق يخوّل صاحبه سلطة مباشرة

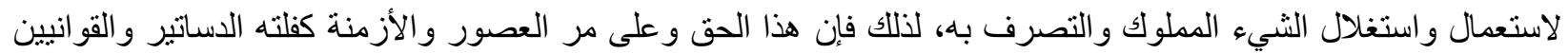

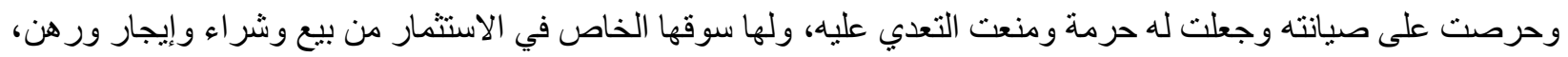

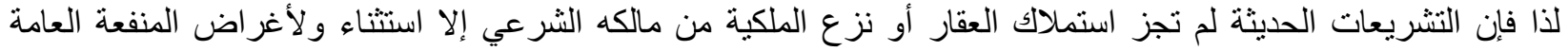

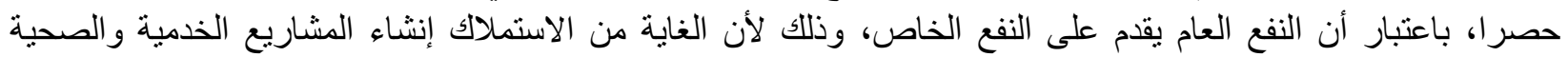
و التربويه و التي تحدد أنو اعها.

الكلمات المفتاحية :الاستيلاء، الملكية، التعويض، نزع الملكية ، التصرف القانوني 


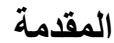

حق الملكية هو حق من الحقوق العينية الأصلية التي ترد على شيء معين ويخول هذا الحق صاحبهُ ميزتي التتبع والتقدم، وهي خصائص يشترك فيها سائر الحقوق العينية الأخرى. وإضافة لانفر اد هذا الحق بخصائص أخرى دون سواه من الحقوق العينية الأخرى إضافة لانفر اد هذا الحق بخصائص أخرى كونه حقاً جامعاً، مانعاً، رائحاً، لأنه حق جامع لكونهُ يخول صاحبهُ جميع السلطات المحتملة على ذلك الثيء والتي تمكنه من الاستفادة من هذا الحق والحصول على جميع المزايا وفي الاستعمال و الاستغلال والتصرف، كما أنه حث مانع، يعني بأن المالك وحده سيتأثر بمزايا ملكه دون سواه ومن حقه أن يمنع أي شخص يريد مشار كتهُ في ذللك، كما أنه حق دائم لكونه يبقى مادام محلهُ قائماً ولا سيسقط بعدم الاستعمال وكذلك عدم جواز توقيته بزمن

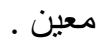

وقد عرف المشرع العر اقي حق الملكية في المادة 1048 من القانون المدني العراقي (رقم 40لسنة 1951) وذلك بالنص ((هو الملك التام الذي من شأنه أن يتصرف به المالك تصرفاً مطلقاً في ما يملكه عيناً ومنفعة و استغلالاً فيتفع بالعين المملوكة وبغلتها وثمار ها ونتاجها ويتصرف في عينها بجميع التصرفات الجائزة)) وقد نقل المشرع العر اقي هذا التعريف من كتاب مرشد الحيران بصورة حرفية من نص المادة (11) . وقد مرت الملكية بمر احل جديدة تبعاً لتطور المجتمعات واستمر هذا التطور حتى أصبحت ملكية فردية كما كان للتطورات الاجتماعية و الاقتصادية و الفكرية .

وكان لها أثر ها في توجيه الملكية وجهة اجنماعية حسب منظور البعض، في حين يرى البعض في ذلك انكار اً لفكرة الحق ذاتها وأن وصف الملكية فإنها وظيفة اجتماعية يعد متطرفاً.

فالمالك يباثر سلطته لتحقيق مصلحته الخاصة أما مصلحة الجماعة فتحقق بصورة غير مباشرة، فالأصح أن يقال إن للملكية ونيفة اجتماعية.

وقد حرصت جميع التشريعات الحديثة على صيانة هذا الحق ولم تجز نزع الملكية إلا استثناء بل أنه أصبح من الحقوق المنصوص عليها في الدساتير ومنها الدستور العر اقي لعام (2005) وبالتالي أصبح هذا الحق حقاً دستورياً لا يمكن للتشريعات أن تتعارض معهُ و إلا تعرضت للرقابة الدستورية ..

$$
\text { وقد جاء هذا الحق في نص المادة (23) من دستور جمهورية العر اق التي جاء نصها كالآتي: }
$$


أو لاً : الملكية الخاصة مصونة ويحق للمالك الانتفاع بها و استغلالها و التصرف بها في حدود القانون . ثانياً : لا يجوز نزع الملكية إلا لأغر اض المنفعة العامة مقابل تعويض عادل وينظم ذلك بقانون . ثالثاً : للعر اقي الحق في التملك في أي مكان في العراق و لا يجوز لغيره تملك غير منقول إلا إذا أثبت بقانون . ب- يحضر التملك لأغراض التغيير السكاني .

وبعد أن تكلمنا عن هذا الحق العيني الأصلي وما يتمتع به من خصائص وبإيجاز وبصورة عامة كمنطلق لتحدثنا عن الاستملاك وما هو الغرض منه وما هي أنو اعه وما هي الطبيعة القانونية للاستملاك، لذلك سنتناول في هذا المبحث ثلاثة مطالب سنتكلم

$$
\text { في المطلب الأول منها : المبحث الأول : تعريف الاستملاك والغرض منه . }
$$

المبحث الثالث : الطبيعة القانونية للاستملاك .

\section{المبحث الأول : التعريف بالاستملاك}

يتكلم هذا المطلب في الفرع الأول منه عن تعريف الاستملاك وفي الفرع الثاني عن الغرض من الاستملاك.

$$
\text { المطلب الأول : تعريف الاستملاك }
$$

ولبيان تعريف الاستملاك يتطلب ذللك تصوير معناه لغة واصطلاحاً.

\section{أولاً : تعريفه لغةً}

الاستملاك لغةً: هو تملك الثيء وحيازتهُ والتصرف به تصرف المالك [2]كما عرف في اللغة: بأنه رفع ونزع يد المالك عن

$$
\text { ملكهُ و إعطائه إلى الغير لقاء تعو يض مناسب. [3] }
$$

ونزع الثيء في اللخة يعني خلعه وسلبه (نزع فلان كذا أبي سلبه)، فالاستملاك ونزع الملكية هما معنيان متر ادفان يراد منهما أخذ الملك من صاحبهُ جبراً و هما وجهان لعملة واحدة من الناحية اللغوية . و ومنى الاستملاك هو من الفحل استملك . 
و استملك بتملك استملاكاً فهو مستملك، و المفعول مسنمللك استملك قطعة أرض نزع ملكيتها حرم مالكها من ملكيتها ووضع اليد عليها استملاك (اسم) استملاك (مصدر إستملك). [4]

\section{ثانياً : تعريف الاستملاك اصطلاحاً}

يعرف الاستملاك اصطلاحاً بأنه حرمان المالك من ملكه للمنفعة العامة لقاء تعويض عما يناله من ضرر. [5] ويعرف أيضا بأنه نزع جبري للملكية الخاصة اقتضت ضرورات الصالح العام، وهو استثناء من القو اعد العامة التي توجب احترام الملكية الفردية وكافة الحقوق الناشئة عنها، و هو ينطوي على طابع الجبر و إلار غام و الإذعان. [6] و هنالك من يرى بأنه لابد من التعريف من الناحية القانونية بين مصطلح الاستملاك ومصطلح نزع الملكية، إذ أن الاستملاك ينصرف أي طلب الاستملاك رضا واتفاقاً بين الطرفين في حين أن نزع الملكية ينضوي على طابع الجبر وإلارغام والإذعان ولهذا سماه المشرع المصري نزع الملكية للمنفعة العامة أو التحسن. [7] و هنا فإن التسمية الواردة في التتريع المصري متنفرة لأن الاستملاك لا ينصرف فقط إلى طلب الاستملاك رضاءً واتفاقاً إنما ينصرف أيضا إلى مفهوم نزع ملكية العقار جبراً، لأن عدم توصل الطرفين لاتفاق بهذا الخصوص يدفع المستملك لاستملاك ذلك العقار قضائياً وهو نزع جبري لملكية العقار لقاء تعويض مناسب، وبالتالي فإن الاستملاك في مفهومه ينطوي على هذين المعنيين . وبالتالي فهو أكثر شمو لاً من مفهوم نزع الملكية وكان المشرع العر اقي موفقاً في ذلك. ثالثاً : أما تعريف الاستملاك قانوناً تم تعريف الاستملاك قانوناً تعريفات متعددة وذلك حسب الأزمنة التي صدر فيها هذا القانون وهي في العراق : * قانون الاستملاك للأموال غير المنقولة رقم (43) لسنة 1934 الملغي حيث عرف الاستملاك في م1 منه على أنه (( هو نزع ملكية العقار لنفع عام ولقاء تعويض عادل يعني به وجب هذا القانون)) . * كما عرفه قانون الاستملاك رقم (57) لسنة19601 الملغي في م1 منه في ف1 بأنه (( نزع ملكية العقار لنفع عام ولقاء تعويض عادل بيين بموجب هذا القانون )). 
إن التعريف الأخير كان أكثر تحو لاً من التعاريف الواردة في القوانين السابقة، وذلك لكونه قد نص صر احة على أن نزع ملكية العقار لا يقتصر على حق الملكية فقط بل يحتوي ذلك أيضا للحقوق العينية الأصلية المتعلقة به، كما أنه قد يقتصر على هذه الحقوق العينية إذا كانت القطعة مملوكة للجهة طالبة الاستملاك. [8] * أما بالنسبة لقانون الاستملاك النافذ رقم 12 لسنة 1981 المعدل، فإنه لم يرد فيه تعريفاً محداً للاستملاك أو نزل ملكية العقار وجاء خلافاً للقو انين السابقة بهذا الخصوص، وبذلك فإنه وقد تعمد عد إيراد تعريف للاستملاك و عدم الإشارة إلى أنه لا يكون إلا للمنفعة العامة، ولكنه حرص في مقابل ذلك على تنظيم إحكام التعويض بشكل مفصل، وأحسن فعل المشرع في نركه الباب مفتوحاً للفقه و القضاء لتحديد مفهوم الاستملاك، لأن إير اد مثل هذا التعريف قد يجعل من نطاق تطبيق القانون المذكور ضيقاً إذا ما تم إغفال جانب معين من الجو انب المتعلقة بالاستملاك. [9]

\section{المطلب الثاني : الغرض من الاستملاك}

عادة يجري نزع ملكية العقار ات من قبل الدولة لأغراض المنفعة العامة ويتم التعويض عنها وفقاً للقانون، وبذلك لا يجوز نزع الملكية إلا إذا كان ذلك يحقق منفعة عامة كونها الركن الأساساي الذي يعول عليه لصدور أي قرار بهذا الخصوص فكلما كان هناك نفع عام جاز نزع الملكية .

كانت الغاية أو الغرض من وراء نزع الملكية في ظل الفقه إلاسلامي وما أجازه الفقهاء في ذلك كانت متمثلة بجواز أخذ الملك جبراً على مالكه لتوسعة مسجد أو طريق أو نحوهما إذا احتاج العامة إلى توسعة ذلك، وبالتالي يتيح نرجيح المصلحة العامة و هي مصلحة الناس على مصلحة الفرد، وأصدر الأمر في نزع الملكية هو الترجيح من بين المصالح. ولكن يشنرط في ذلك الترجيح أن تكون المصلحة العامة (جدية) وذات أهية كبيرة وهي تختلف باختلاف الظروف والأحوال الذي يحدد هذه المصلحة ويقرر أهميتها هو (الإمام) أو من ينيبهُ وليس لأحد أن يحتج عليه وتصرف الإمام على الرعية منوط بالمصلحة. [10] و إذا قلنا بأن المصلحة العامة مقدمة على مصلحة الفرد فليس معنى ذلك أن يضار الفرد أو يضيع حقه بل يجب أن يدفع ثمن المثل لمن انتزع ملكه، و هذا يستفاد مما قرره الفقهاء في المذاهب الإسلامية. [11] وفي التشريع العراقي ومن خلال الإطلاع على نصوص قوانين الاستملاك الملغاة منها وعلى سبيل الحصر لأغر اض المنفعة العامة كان المشرع العر اقي يجيز الاستملاك وبمعنى أدق أي كان قد حدد الأغر اض التي تعتبر نفع عام ويمكن إجمالها بالآتي : أولاً الأغر اض العسكرية . 


$$
\begin{aligned}
& \text { ثانياً : الأغر اض المتعلقة بمشاريع الري والبزل . } \\
& \text { ثالثاً : الأغر اض المتعلقة بالصحة العامة . } \\
& \text { رابعاً : الأغر اض المتعلقة بالثروات الطبيعية واستغلالها . } \\
& \text { خامساً : الأغر اض المتعلقة بالتخطيط و التنظيم العمر اني و البلديات . } \\
& \text { سادساً : الأغر اض المتعلقة بالإسكان و المباني العامة . } \\
& \text { سابعاً : الأغر اض المتعلقة بتجميل وتحسين المدن . } \\
& \text { ثنامناً : الأغر اض المتعلقة بإنشاء المزارع النموذجية و الأسواق العصرية . } \\
& \text { تاسعاً : الأغر اض المتعلقة بتنفيذ المعاهدات والاتفاقيات الدولية . }
\end{aligned}
$$

أما بالنسبة لقانون الاستملاك النافذ رقم 12 لسنة 1981 المعدل فإنه لم يرد فيه تعريفاً أو معيارً أو شرطاً معيناً لتحقيق المنفعة ولم يرد فيه ما يشير إلى الأغر اض التي تدخل ضمن هذا المفهوم من حيث نص م (1) .

$$
\text { حيث جاء فيه إلى أن هذا القانون يهدف إلى : }
$$

أولاً: تنظيم استملاك العقار والحقوق العينية الأصلية المتعلقة به من قبل دوائر الدولة والقطاع الاشتراكي تحقيقاً لأغراضها وتنفيذاً لخططها ومشاريعها.

أما بالنسبة للمادة (9) من نفس القانون فقد نصت على دوائر الدولة والقطاع الاشتر اكي التي يحق لها استملاك العقار قانوناً أن تطلب استملاك أي عقار أو جزء منه أو الحقوق العينية الأصلية المتعلقة به وفق أحكام هذا القانون لتنفيذ مشاريعها وتحقيق أغر اضها . كما أن المادة (10) من ذات القانون نصت على المستملك تقديم طلب الاستملاك إلى محكمة البداءة على موقع العقار يؤيد فيه عدم وجود مانع خطي أو قانوني من الاستملاك باستثناء الاستملاك لأغراض عسكرية مرفقاً به الوثائق المطلوبة . ويرى البعض أنه من الضروري تحديد أغراض النفع العام تشريعاً كما هو الحال في القوانين السابقة وأن تتاح إمكانية القياس عليها أي اللجوء إلى التحديد الإداري لأغراض النفع العام ولكن مع رقابة القضاء عليها تحوطاً من انحرافها عن الصالح 


\section{المبحث الثاني : أنواع الاستملاك}

لقد خصص المشرع العر اقي الباب الثاني من قانون الاستملاك رقم 12 لسنة 1981 المعدل لبيان أنواع الاستملاك وقد حصر ها بثلاثة أنواع هي :

$$
\begin{aligned}
& \text { 1- الاستملاك الرضائي . } \\
& \text { 2- الاستملاك القضائي . } \\
& \text { 3- الاستملاك الإداري . } \\
& \text { وسنتنأولها تبعاً في هذا المطلب . }
\end{aligned}
$$

\section{المطلب الأول : الاستملاك الرضائي}

و هو في مفهومه وظاهره اللفظي، اتفاق رضائي بين طالب الاستملاك والمطلوب الاستملاك منه على استملاك عقار، وحق عيني عليه يرضي صاحب العقار ، شريطة أن يكون الاستملاك للمنفعة العامة، فالأصلان ملك لا يؤخذ من صاحبه دون رضاه و هذا المبدأ على نقيض مفهوم الاستملاك الذي أشرنا له سابقاً، والذي يتعلق بنزع الملكية من صاحبها جبراً ومن المفترض أن يكون الاستملاك الجبري إن امتتع صاحب العقار المطلوب استملاكه عن الإجابة لطلب الاستملاك والتنازل عن عقاره برضاه د13 [13 الحاجة إلى الاستملاك منه جبر اً.

وبالتالي فإن الاستملاك الرضائي هو الاستملاك الي يتم عن طريق التفاوض بين المستملك والمستملك منه فيجوز لدوائر الدولة و القطاعين الاشتر اكية والمختلطة الاتفاق مع مالك العقار أو الحق العيني الوارد على عقار على استملاكه رضاء.

ولقد خصص المشرع العر اقي المواد (4 -8) من قانون الاستملاك لبيان أحكام الاستملاك الرضائي والطريقة التي يتم بموجبها عند موافقة صاحب العقار على التنازل عن عقاره لقاء بدل يتفق عليه مع المستملك دون الحاجة إلى إجراءات الاستملاك الجبرية فالاستملاك الرضائي في حقيقة الأمر ليس إلا بيعاً رضائياً لا يختلف عن بقية البيوع. [14] ومن خلال نصوص م (4 - 8) من قانون الاستملاك نلاحظ بأن المشرع العراقي قد أعطى الحق لدوائر الدولة والقطاع الاشتر اكي التي يحق لها تملك العقار قانوناً والاتفاق مع صاحب ذلك العقار على استملاكه أو استملاك الحق العيني المتعلق به رضائياً لقاء تعويض تقدره هيئة التقدير المشكلة بموجب هذا القانون، كما اشترط الحصول على موافقة جميع الثركاء إذا كان العقار المراد استملاكه مملوكاً على الثيوع فالأصل هو موافقة المالك شخصاً واحداً كان أو اكثر من ذلك . 
حيث نصت م 4 من قانون الاستملاك على (لدو ائر الدولة والقطاع الاشتر اكي التي يحق لها تملك العقار قانوناً أن تتفق مع مالك العقار أو الحق العيني المتعلق به على استملاكه رضاءً عيناً أو نقداً، يبدل الذي تقدره هيئة التقدير المشكلة بموجب هذا القانون و إذا كان العقار شائعاً فيلزم موافقة جميع الثركاء فيه على ذللك، وأن اشترط مو افقة جميع الثركاء على الاستملاك متأتية من أن كل شريك يعتبر أجنبياً في حصة الآخر وليس له أن يتصرف فيها بأي شكل من الأشكال دون رضاه، حيث نصت (م 1062 ف1) من القانون المدني على كل و احد من الشركاء أجنبي في حصة الآخر وليس له أن يتصرف فيها تصر فاً مضر اً بأي وجه كان من غير رضاه، ومن الناحية العملية لهذا النوع من الاستملاك يشترط في المستملك أن يكون متمتعاً بالشخصية المعنوية أو لاً لتملك الحقوق و اكتساب الملكية العقارية، كي يكون له طلب الاستملاك، إذ مثلاً نجد بأن مديرية ما في وزارة ما قد تلجأ إلى الاستملاك دون نوفر الثروط فيها، لذلك فإن طلبها يكون محسوماً بالرد للسبب المذكور. [15] أما إذا كان من بين الثركاء محجور لذاته (صغير - مجنون - معتوه) أو كان محجوراً عليه من قبل المحكمة (سفيه أو ذو غفلة) أو كانت تصر فاته مقيدة بقرار قانوني أو قضائي فيجب أخذ مو افقة من ينوب عنهم قانوناً على الاستملاك وبإذن من الجهة التي حددها القانون كمديرية رعاية القاصرين أو المحكمة. [16] ويتم الاستملاك الرضائي بعد حصول الاتفاق المبئي بين المستملك والمستملك منه على استملاك العقار ، يقدم المستملك طلبه لهيئة التقدير يطلب فيه تحديد التعويض الواجب دفعه للمستملك منه وفقاً للأسس الواردة في قانون الاستملاك، ويشعر دائرة التسجيل العقاري المختصة لوضع إثارة عدم التصرف على ذلل العقار لضمان بقاء الأوضاع القانونية على حالها دون تغيير لحين إكمال إجراءات الاستملاك، وتقوم هيئة التقدير بتحديد البدل الواجب دفعه للمستملك منه وبعد إصدارها لقرارها بهذا الخصوص، يتيح تبليغ الطرفين بالقرار من قبل رئيس هيئة التقدير وكذلك تبلغ به دائرة التسجيل العقاري المختصة . إن قرار هيئة التقدير يصبح باتاً وملزماً للطرفين وغير قابل للطعن به إذا وافق عليه الطرفان تحريرياً أو مرت عليه عشرة أيام اعتبار اً من تاريخ تبليغها به و عدم حصول اعتر اض عليه لدى ذات الهيئة من قبل الطرفين، أما إذا اعترض أحد الطرفين على التقدير خلال المدة المذكورة فتعتبر الإجراءات الاستملاك الرضائي ملغاة ويكون رئيس هيئة التقدير ملزماً بإثعار دائرة التسجيل العقاري المختصة برفع إشارة عدم التصرف عن العقار موضوع الاستملاك .

ثم يلزم المستملك بايداع بدل الاستملاك لدى دائرة التسجيل العقاري لموقع العقار إذا كان البدل تقديرياً وكذلك تسجيل العقار المستبدل به باسم المستملك منه في دائرة التسجيل العقاري، إذا كان التعويض عينياً خلال مدة ستين بوماً اعتباراً من تاريخ تبليغه بقرار هيئة التقدير مالم يتفق الطرفان خلاف ذللك، وهذا يعني أن الطرفين بإمكانهما الاتفاق على مدة أقل أو أكثر من المدة 
المحددة قانوناً وهي ستون يوماً لتسديد بدل الاستملاك وبالر غم من القانون لم ينص على المدة إلا أننا نرى ضرورة أن يكون هذا الاتفاق تحريرياً وإيداعه إلى هيئة التقدير أسوة بموافقة الطرفين التحريرية على قرار هيئة التقدير بخصوص بدل الاستملاك المنصوص عليها في البند أولاً من م6 من قانون الاستملاك. كما بلتزم المستملك منه بتسليم العقار للمستملك بالحالة التي كان عليها عند التقدير خلال مدة ثلاثين يوماً تبدأ من تاريخ إيداع البدل لاى دائرة التسجيل العقاري المختصة مالم يتفق الطرفان على خلاف ذلك .

و هذا يعني أن الطرفين بإمكانهما أيضا الاتفاق على مدة قد تزيد أو تقل على هذه المدة المحددة قانوناً للتسليم وهي ثلاثون يوماً [17] .

ويعتبر الاتفاق الرضائي على الاستملاك قرار هيئة التقدير هي الأساسا لتسجيل العقار باسم المستملك بعد إيداع بدل الاستملاك وليس هناك حاجة لأي إجر اءات أخرى بهذا الخصوص إلى ذلك أشارت م 7 من قانون الاستملاك بنصها على : أولاً: على المستملك إيداع بدل الاستملاك لدى دائرة التسجيل العقاري لموقع العقار أو تسجيل العقار المستبدل به باسم المستملك منه في حالة التعويض العيني خلال مدة ستين يو ماً من تاريخ تبليخه بقرار هيئة التقدير مالم يتفق الطرفان على خلاف ذلك . ثانياً : يلتزم المستملك منه بتسليم العقار المستملك إلى المستملك بالحالة التي كان عليها عند التقدير خلال 30 يوماً من تاريخ إيداع البدل لدى دائرة التسجيل العقاري دون الحاجة لأية إجراءات أخرى مالم يودع المستملك بدل الاستملاك لدى دائرة التسجيل العقاري المختصة أولم يقم بتسجيل العقار المستبدل به باسم المستملك منه خلال المدة القانونية المحددة في البند أولاً من م 7 من قانون الاستملاك المارة الذكر فاللمستملك منه إلغاء موافقته على الاستملاك و إثعار المسنملك منه ودو ائر التسجيل العقاري المختصة بذلك تحريرياً وتعتبر جميع الإجر اءات المتخذة بهذا الشأن ملغاة. [18]

المطلب الثاني: الاستملاك القضائي

قد لا يتوصل الطرفان، المستملك والمستملك منه في أغلب الأحيان إلى صيغة توافقية لاستملاك العقار فلا يبقى أمام الجهة طالبة الاستملاك والتي تضعها ضرورات المصلحة العامة لاستملاك ذلك العقار، إلا النوع الثاني من أنواع الاستملاك وهو الاستملاك القضائي والذي ينطبق عليه مفهوم نزع الملكية جبراً من صاحبها لأغراض المنفعة العامة، وقد تناول المشرع العر اقي هذا النوع من الاستملاك في المواد (6 -12) من قانون الاستملاك النافذ، والذي رسم بموجبها الطريق لاستملاك العقار من صاحبه قضائياً لقاء تعويض عادل حيث صـار لهذا النوع من الاستملاك بعد تعذر الاتفاق مع المستملك منه على الاستملاك الرضائي عندما يكون لا مناص من اللجوء إلى أحكام الاستملاك القضائي ومن خلال استقراء نص م 9 من قانون الاستملاك 
و الذي ذكرناه سابقاً في هذا البحث، نجد بأن المشرع العراقي أعطى الحق فقط لدوائر الدولة والقطاع الاشتراكي التي يحق لها بتملك العقار قانوناً أن تطلب استملاك أي عقار لغرض تتفيذ مشاريعها وتحقيق الأغر اض التي تجعل على تتفيذها، ومن الجدير بالذكر إن امتداد سلطان دوائر الدولة ونشاطها إلى كل جزء من البلاد كون الضرورة تقتضي أن تكون ممارستها للتصرفات العقارية مطلقة فإنها لها طلب الاستملاك دون قيد .

وبالتالي استتاداً لذلك فإن حصر حق طلب الاستملاك بدوائر الدولة والقطاع الاشتراكي يعني بأنه هناك جهات أخرى كالمنظمات الإنسانية و الجمعيات و النقابات و غير ها، و لا يحق لها طلب الاستملاك بالر غم من كونها تهدف في أعمالها لتحقيق المصلحة العامة لصراحة نص م9 من قانون الاستملاك ولكون هذه الجهات لا تندرج تحت مفهوم دوائر القطاع

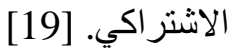

أما بالنسبة لنص المادة 10 من قانون الاستملاك والتي مر ذكرها في هذا البحث فقد رسمت هذه المادة الإجراءات الواجب اتباعها لتقديم طلب الاستملاك ابتداءً من تقديم الطلب إلى محكمة البداءة موقع العقار مرفق معه ما يؤيد عدم وجود مانع تخطيطي أو قانوني من استملاك ذلك العقار فالاختصاص هنا ينعقد حصراً لمحكمة بداءة موقع العقار ولا يجوز تقديمه لأي محكمة أخرى أو جهة أخرى. [20] من المعروف أن المو افقة التخطيطية تعطى من دائرة التخطيط العمر اني الموجودة في كل محافظة وتتعلق بالعقار ات الموجودة داخل الحدود البلدية للمدن، أما إذا كانت خارج الحدود البلدية فلا يوجد مبرر لجلب هذه الموافقة، لأن دائرة التخطيط العمراني تكون غير معنية بإعطاء المو افقة .

أما في حالة عدم إعطاء المو اققة التخطبطية فيجب أن يكون القرار مسبباً ومبرراً، وأن يكون عدم الموافقة لأسباب مقبولة و منطقية قانوناً وإذا ما ثبت تعسف دائرة التخطيط العمر اني بعدم إعطاء المو افقة فبإمكان المحكمة إصدار قر ار باستملاك العقار رغم عدم وجود المو افقة، لأن الأمر في نهايته يخضع لتقدير محكمة البداءة.

كما أن المادة المذكورة اشترطت بالإضافة للمو افقة التخطيطية أن برفق مع طلب الاستملاك الوثائق التالية : 1- نسخة من آخر سجل للعقار أو تأييد من دائرة التسجيل العقاري بعدم تسجيله. 2- خارطة مصدقة من دائرة التسجيل العقاري مؤشر عليها المساحة المطلوب استملاكها .

3- بيان باسم مالكي العقار أو حائزي الحقيقيين إن كان غير مسجل وكذلك عناوينهم أو عنوان أحدهما على الأقل. [21] 
بعد استيفاء الطلب للشروط المذكورة تحدد المحكمة موعداً للنظر به خلال (10) أيام اعتبار اً من تاريخ تسجيله لديها، وتطلب من دائرة التسجيل العقاري عدم إجر اء أي تصرف على العقار المطلوب استملاكه وإشعار ها بأي تصرفات سجلت على العقار و أن ذللك متعارف عليه في العمل القضائي - بوضع إثـارة عدم التصرف على العقار، الغاية من ذلك هو لضمان بقاء الأوضاع القانونية على حالها دون تغيير حتى يتم الفصل في موضوع طلب الاستملاك .

وبذللك فإن محكمة البداءة إذا ما نظرت في طلب الاستملاك و أصدرت قرارها دون استكمال الإجراءات الثكلية المنصوص عليها في قانون الاستملاك ومن بينها وضع إثارة عدم التصرف على العقار وربط خارطة العقار وصورة قيده، فإن قرارها و الحالة هذه يكون معيباً من الناحية الشكلية ويكون عرضة للنقض في حالة الطعن به تمييزياً من قبل الخصوم . وبعد استكمال الإجر اءات المشار إليها أعلاه تقوم محكمة البداءة بدعوة الطرفين الحضور في الموعد المحدد، فإذا كان استملاك من أكثر من واحد أو كان من بينه متوفي جاز لها تبليغ أحدهم ودعوة الباقين عن طريق الإعلان في صحيفة محلية يومية واحدة بموجب اسمائهم الواردة في آخر سجل العقار، ويعتبر ذلك تبليغاً للشركاء كافة وكذلك ورثة المتوفين منهم، أما إذا كان العقار غير مسجل فيبلغ الحائز الحقيقي للعقار المر اد استملاكه بذات الطريقة المشار إليها أعلاه المتعلقة بتبليغ مالكي العقار ات، وبذلك فإن المشرع راعى حقوق حائزي العقارات الغير المسجلة أسوة بمالكي العقار ات المسجلة باسمائهم إيماناً منه بتعويض جميع ذوي العلاقة تعويضاً عادلاً قبل نزع ملكية تلك العقار ات واحتر اماً منه لحق الملكية. [22] المطلب الثالث: الاستملاك الإداري وتمييزه عن الاستيلاء المؤقت

الاستملاك الإداري هو اتفاق بين شخص معنوي وشخص معنوي آخر على نقل ملكية عقار أو حق عيني عقاري يعود لأحدهما إلى الآخر مقابل تعويض يتحدد بإر ادة الطرفين [23]، وقد تناول المشرع العر اقي هذا النوع من أنواع الاستملاك في المواد (م) 22 - 25) من قانون الاستملاك وهو صورة جديدة من صور نزع الملكية لم تكن موجودة في قوانين الاستملاك السابقة (الملغاة) حيث نصت م 22 من قانون الاستملاك رقم 2 لسنة 1981 المعدل على (إذا كان العقار أو الحق العيني المطلوب استملاكه يعود إلى دو ائر الدولة أو القطاع الاشتر اكي أو الأوقاف فيجري استملاكه إدارياً ويتحدد التعويض وباتفاق الطرفين) . وبذللك فإن القانون استنتى من الاستملاك الإداري العقار ات الموقوفة، لأن الوقوف يترتب عليهز زوال مالك الو اقف عن الموقوف فيتيح عليه التصرف و لأن العمل الو اقف ناتج عن أحكام الثرعية فليس من الصواب حرمانه من المحافظة عليه بتطبيق قانون آخر مخالف لقصر الو اقف لذلك لا يتفق على نقل ملكية الغير إلا بنص القانون كما هو الحال في الاستملاك القضائي الذي بموجبه تنزع ملكية العقار الموقوف جبر اً لتحقيق المنفعة العامة. [24] 
ومع أن الوقف من الحقوق العينية الأصلية ولكونه من النظام العام فلا يصح أن يكون محلاً للالتز ام أصلاً و على هذا الأساس لا يجوز استملاك العقار ات الموقوفة استملاكاً إدارياً. [25]

إذا اتفق طرفا الاستملاك فلا يوجد مشكلة، أما إذا حصل خلاف بينهما فيتم الفصل في هذا الخلاف من قبل الوزير المختص إذا كان طرفا الاستملاك من دوائر الدولة التابعة لوزارة واحدة، أما إذا كان الطرفان يتبع كل منهما إلى وزارة أخرى ولم يكونا تابعين لوزارة واحدة فإن الفصل في الخلاف الحاصل بينهما حول الاستملاك الإداري يكون من اختصاص مجلس الوزراء ويكون القرار الصادر من الوزير المختص أو مجلس الوزراء حسب مقتضى الحال باتاً وملزماً للطرفين (م23) .

أما بالنسبة لمبلغ التعويض في الاستملاك الإداري فإنه يخضع لاتفاق الطرفين ابتداءً، أما إذا اختلفا بهذا الخصوص فلكل منهما الحق بأن يطلب من هيئة التقدير الواردة في قانون الاستملاك تحديد ذلك التعويض وفقاً للأسس الواردة في ذات القانون ويكون قرار هيئة التقدير باتاً وملزماً للطرفين. [26]

أما بالنسبة لتسجيل العقار المطلوب استملاكه باسم المستملك في دائرة التسجيل العقاري فإنه يتخذ اتفاق الطرفين أساساً للتسجيل كما يتخذ من قرار هيئة التقدير أساساً للتسجيل إذا كانا قد اتفاقا على الاستملاك الإداري وتركا موضوع تقدير التعويض لهيئة التقدير، أما إذا لم يتفقا اصلاً على الاستملاك فيتخذ من قرار الوزير المختص أو مجلس الوزراء وقرار هيئة التقدير أساسا للتسجيل وفي جميع الأحو ال يحب أن يتم تسديد البدل للمستملك منه أو إيداع ذلك البدل لدى دائرة التسجيل العقاري لموقع العقار حتى ينم التسجيل حيث نصت على ذلك م 25 من قانون الاستملاك. [27]

و أخيراً لابد من الإشارة إلى أن مثل هذه الحالات لا تندرج من ضمن أنواع الاستملاك ولكن من الضروري الإشارة إليها لتميز ها عن الاستملاك الإداري ألا وهي ما تسمى بالاستلاء المؤقت والتي أوردها المشرع العر اقي في م (26 -28) من قانون الاستملاك رقم 12 لسنة 1981 المعدل، حيث أجاز لدوائر الدولة والقطاع الاشتراكي، في الظروف الاستثنائية الطارئة كالفيضانات وتفتي الأوبئة كالكوليرا مثلاً أجاز لها الاستيلاء مؤقتاً على أي عقار على أن تحدد مدة الاستيلاء في قرار الاستيلاء على أن لا تزيد مدة الاستيلاء في جميع الأحو ال على السنتين . [28]

\section{المبحث الثالث : الطبيعة القانونية للاستملاك}

بعد أن تطرقنا إلى الحديث عن أنواع الاستملاك وماهية الإجراءات المتبعة في كل نوع منها ولا يوجد أبي مبرر في عبور هذه الفقرة من دون بيان للطبيعة القانونية للاستملاك، ومن خلال بيان أنواع الاستملاك واجر اءاته نعد بأنه خلاف في خصوص الطبيعة القانونية لطلبات الاستملاك (رضائي كان أو استملاكاً إدارياً ) وذلك لأن طلبات تقدم إلى جهات غير قضائية . 
لكن الخلاف يثور بمناسبة الحديث عن الاستملاك القضائي حيث يثار التساؤل هل أن هذا الاستملاك مجرد طلب أم أنه دعوى بما أنه يقدم إلى جهة قضائية وفي حالة كونه دعوى فلابد أن نطبق نصوص قانون المر افعات المدنية العر اقي رقم 83 لسنة

بالنسبة للإجر اءات التي لم يرد بشأنها نص في قانون الاستملاك رقم 12 لسنة 1981 فإن هذا القانون هو القانون الإجرائي لكافة القو انين في حالة عدم ورود نص وبالتالي سنبحث في فرعين المفهومين أي الطب و الدعوى وأيهما أصح على الاستملاك القضائي :

المطلب الأول: الاستملاك طلب وليس دعوى

برى أصحاب هذا الر أي بأن الاستملاك هو طلب كسائر الطلبات و لا يحمل مفهوم الدعوى الواردة في قانون المر افعات المدنية وقد أسس صاحب هذا الر أي رأيهم على الآتي : 1- إن المشرع قد ذكر في نص المادة 9 من قانون الاستملاك عبارة (أن تطلب استملاك) . 2- كما إن نص المادة (12) منه ورد في الفقرة أو لاً: تعين المحكمة مو عداً للنظر في طلب الاستملاك . 3- كما إن الفقرة الثانية من نفس المادة مارة الذكر (نصت أنه قررت المحكمة رد طلب الاستملاك ) و إن هذه النصوص سبق أن ذكرناها في هذا البحث طلب الاستملاك على وجه الاستعجال ويجري تفهيم القرار للطرفين، و إذا كان أحدهما غائباً أو كان المستملك منهم منوفي فيتم تبليغ القرار وفقاً للبند ثايناً من المادة 11 من هذا القانون. [29] كما أن أصحاب هذا الرأي قد دعموا رأيهم بأمور أخرى كان أبرزها : 1- إن المشرع العر اقي استعمل في قانون الاستملاك النافذ مصطلح إلغاء الاستملاك وسحبه وذللك للالالة على الطبيعة الإدارية له، فهو لم يستعمل المصطلحات الواردة في قانون المرافعات المدنية فيما يتعلق بالقرارات الصادرة في الدعاوي مثل النقض، الأبطال وتأييد القرار وتصديقه أو فسخه عند الطعن به . 2- إن الأعمال والإجراءات المتعلقة بالاستملاك هي إجراءات إدارية بحتة كونها قد أوكلت إلى هيئات التقدير التي يرأسها قاضي محكمة بداءة موقع العقار، وينظر في طلب الاستملاك بصفته رئيساً للهيئة وفقاً لقانون الاستملاك وليس قانون المر افعات المدنية ـ [30] 
3- إن الرسوم والمصاريف عند صدور القرار باستملاك العقار المطلوب استملاكه وفي جميع الأحوال يتضمنها المستملك حتى لو ثدر قرار مصلحة واستملك العقار حيث نصت المادة 15 ف أولاً من قانون الاستملاك على \{يدفع المستملك بدل الاستملاك مع المصاريف إلى المحكمة نقداً في حالة التعويض النقدي ؛ . . على العكس الرسول و المصاريف في الدعوى التي يتحملها عادة من خسر الدعوى عملاً بأحكام المادة (166) الفقرة (1) من قانون المر افعات المدنية. [31]

4- إذا ما تولدت الحاجة أثناء نظر طلب الاستملاك للمطالبة بالتعويض إن توفرت أسبابه وكان له محل وحصل خلاف بين الطرفين على تقدير فإن ذلك يستوجب إقامة دعوى مستقلة أمام القضاء وبالتالي تكون هنالك دعوى مستقلة عن طلب الاستملاك. [32] ط

5- إن طلب الاستملاك لا يعتبر دعوى وفقاً لمفهومها الوارد في المادة (2) من قانون المر افعات المدنية التي نصت على (الدعوى طلب قانون خاص رسم الجو انب الثكلية والموضوعية العملية عند النظر بطلب الاستملاك والسير فيه ولم يتضمن القانون المذكور في طياته نصاً يشير للإحالة على قانون المر افعات المدنية وتطبيقه في حالة غياب النص في

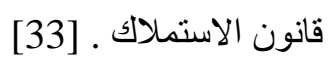

وبالتالي ومن خلال هذه الحجج لأصحاب هذا الر أي فإنهم يرون بإن محكمة بداءة موقع العقار بالر غم من كونها بتت بالطلب إلا أن هذا الطلب ليس بدعوى قضائية وفقاً لقانون المرافعات المدنية، وذلك لانتفاء النزاع بين المستملك و المستملك منه إلا أن المشرع العر اقي أوكل البت في طلب الاستملاك للقضاء، وذلك بسبب الخشية من تعسف الإدارة عند مطالبتها بالاستملاك تجاه الأفر اد وحتى لا تكون في الوقت ذاته خصماً للمستملك منه وحاكماً عليه. [34]

\section{المطلب الثاني: الاستملاك دعوى}

يرى أصحاب هذا الر أي بأن الاستملاك القضائي هو دعوى مستوفية لكافة شروطها القانونية مؤسسين رأيهم أيضا على ما ورد في المادة (2) من قانون المر افعات المدنية رقم 83 لسنة 1969 و التي مر ذكر ها في هذا البحث والتي عرفت الدعوى بأنها طلب شخص حقه من آخر أمام القضاء وبذلك فإن المادة المذكورة حددت شروط الدعوى والتي تتكون من ثلاثة عناصر : أولهما: الطلب الذي ينبغي أن يكون تحريرياً فلا يمكن أن يكون هذا الطلب شفهياً. [35] ثانياً: أن يكون هذا الطلب التحريري منصباً على حق يجوز المطالبة به قانوناً فإذا كان الحق المذكور لا يحق المطالبة به قانوناً فتكون الدعوى واجبة الرد من هذه الناحية . 
ثالثاً: أن يكون الطلب التحريري المنصب على حق مقدماً إلى القضاء، وبهذا تخرج الطلبات المقدمة لجهات أخرى من هذا المفهوم وأن تو افر فيها الثرطين الأول و الثاني وهما المطالبة التحريرية والحق القانوني .

كما أن هناللك من يدعي أن التعريف الوارد في المادة المذكورة أعلاه يترتب عليه أن مفهوم الدعوى يقتصر على مجرد المطالبة

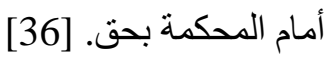

عند نطبيق هذه الشروط الثثلاثة المشار إليها أعلاه على طلب الاستملاك نجد بأن الطلب يقدم تحريرياً إلى القضاء وأن هذا الطلب ينصب على حق منحه القانون لطالب الاستملاك يتمنل باستملاك العقار والحقوق العينية الأصلية الأخرى المتعلقة بـ لأغر اض المصلحة العامة وبذلك فإن العناصر الثلاثة تكون متوفرة في طلب الاستملاك. [37] كما أن المحكمة عادة تضيف لتحققها من الشروط الشكلية والموضوعية الواردة في قانون الاستملاك فإنه يجب أن تتحقق من تمتع طالب الاستملاك بالثخصية المعنوية التي تؤ هله حق إقامة الدعوى حتى يكون أهلاً للخصومة، وهذا ما نصت عليه م 80 من قانون المر افعات المدنية حيث جاء فيها : 1- إذا كانت الخصومة غير منوجهة تحكم المحكمة ولو من تلقاء نفسها برد الدعوى دون الدخول في أساسها . 2- للخصم الن يبدي هذا الرفع في أية حالة تكون عليها الدعوى فإذا ما ثبت عدم تمتع طالب الاستملاك بالشخصية المعنوية التي تؤهله حق إقامة الدعوى فإن المحكمة تقوم برد طلب الاستملاك.

ونستخلص مما تقدم أن القرارات السابقة تبين وبشكل واضح، بأن الاستملاك هو دعوى وبالتالي وفقاً لذلك نجد بأن الاستملاك (دعوى) وذللك لنص المادة 63 من قانون الاستملاك فقد نصت على (تكون القرارات النهائية والاحكام الصادرة بموجب هذا القانون قابلة للتمييز لدى محكمة الاستئناف خلال خمسة عشر يوما، من اليوم النالي لتفهيمها إن كانت وجاهية أو تبليغها إن كانت غيابية ولا يقبل الطعن في القرار التمبيزي بطريق تصحيح القرار التمبيزي . و هذا النص يدل على أن القرارات التي تصدر في الاستملاك الرضائي وكذلك الاستملاك الإداري هي قرارات تكون بناء على طلب إما الأحكام، فإنها تصدر في الاستملاك القضائي وأن الحكم لا يصدر إلا بموجب دعوى. كذلك أن المشرع حدد مدة خمسة عشر وهي دلالة واضحة على اعتبار القرار حكماً صادراً بموجب دعوى كباقي الدعاوي الأخرى، وذللك لأن المشرع اعتبره طلباً لإخضاعه للمدة المتعلقة بالطلبات والأوامر على العرائض وكذلك طرق الطعن المتعلقة بها و النص في قانون الاستملاك صر احة على ذلك . 


\section{الخاتمة}

في نهاية هذا البحث المنو اضع توصلنا إلى النتائج و المقترحات الآتية :

1- إن الاستملاك هو أسلوب استثنائي تتبعه الدولة لغرض الحصول على الأموال العامة ويتضمن حرمان الاشخاص من

أملاكهم الخاصة مقابل تعويض عادل ويجب أن يكون نزع الملكية مقرراً للمنفعة العامة، ويجب أن يكون لنزع الملكية أن على الدولة الموازنة بين المصلحة العامة لغرض نزع الملكية ومصلحة الأفراد .

2- يعتبر نزع الملكية للمنفعة العامة أو الاستملاك بأنه تصرف يتصف بالخطورة وبالنالي قد نصت عليه الدساتير ومنها دستور العراقي لعام 2005 الذي يبين أن نزع الملكية يجب أن يكون للمصلحة العامة ومقابل تعويض عادل وقد أحالت الدساتير على القو انين تبيان كيفية وإجراءات نزع الملكية للمنفعة العامة، ولأهية هذا الموضوع فقد خولت القوانين رئيس الجمهورية أو الوزير المختص أو رئيس الدائرة أو مدير القطاع العام بتقرير المنفعة العامة للعقار موضوع نزع الملكية .

3- إن طلب الاستملاك ينحصر بدوائر الدولة والقطاع الاشتراكي ولا يحق قانوناً للجهات الأخرى طلب الاستملاك إلا

$$
\text { 4- يجب أن يكون الاستملاك لأغر اض المصلحة العامة حصر اً . }
$$

5- إن الاستملاك ينحصر في ثلاثة أنواع هي: (إداري / رضائي/ قضائي) وأن الجهة المستملكة مخيرة بسلوك طريق أي نوع من هذه الأنواع الثلاثة .

1. إن الاستملاك الإداري والاستملاك الرضائي هما طلب وليس هنالك خلاف بخصوص الطبيعة القانونية لهما، أما الاستملاك القضائي فهنالك خلاف بخصوص الطبيعة القانونية له فهنالك من برى بأنه دعوى قضائية وهناك من برى بأنه مجرد طلب يقدم للقضاء ونحن مع رجحان كفة أصحاب الر أي القائل بأنه دعوى قضائية، فلا يمكن اعتبار الاستملاك القضائي مجرد طلب إذ أن ذلك سيؤدي إلى ضياع الأحكام القانونية الخاصة به. 2.التشجيع على الكتابة في هذا المجال من قبل الفقه القانوني ومراعاة الواقع العملي في الجانب القضائي بسبب قلة المصادر التي توضح وتشرح قانون الاستملاك العر اقي النافذ وتبين تفصيل نصوصه وذلك لتوعية بآلية هذا القانون في الاستملاك و التعو يض و أبعاد شبهة التعسف عنه . 
[1][محد طه البشير و غني حسون طه - الحقوق العينية - مطابع مديرية دار الكتب - جامعة الموصل - 1982 - ص23-

[2][ابر اهيم مصطفى واحمد حسن الزيات ومحمد علي النجار، المعجم الوسيط، الجزء الأول مجمع اللغة العربية ، القاهرة -

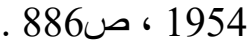

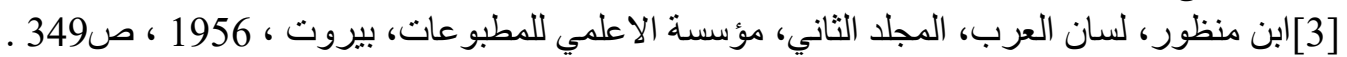

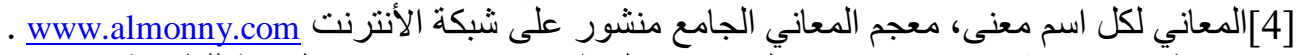

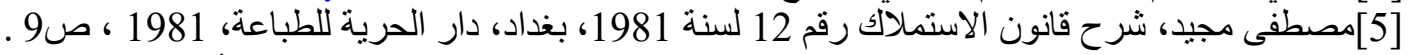

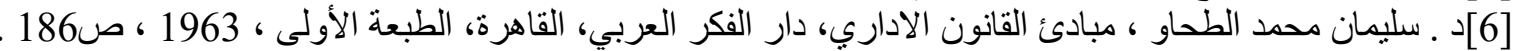
.210، 5[7]

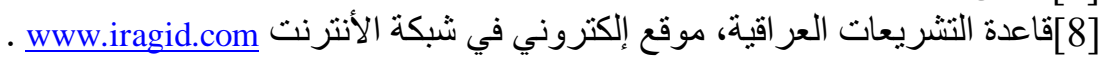
3901[9]

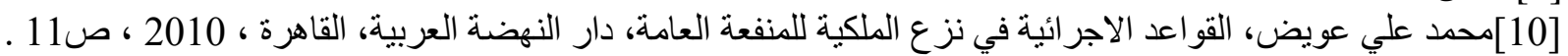

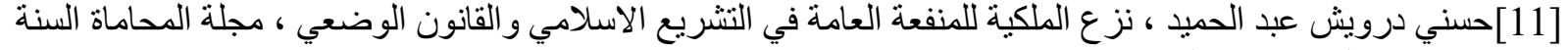

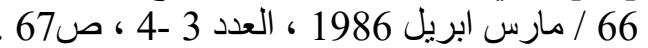
[12]خالد رشيد الدليمي، نزع اليل الملكية للمنفعة العامة، أطروحة دكتور اه مقدمة إلى كلية القانون جامعة بغداد ، 2001 ، ص287 .39 5[13]

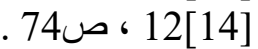

[15] [القاضي شهاب احمد ياسين، الوجيز في شرح قانون الاستملاك، المكتبة القانونية، بغداد، الطبعة الأولى ، 2011 ، ص13

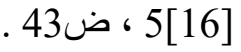
(18) [18]نصت م 8 قانون الاستملاك على (إذا لم يودع المستملك بدل الاستملاك لدى دائرة التسجيل العقاري المختصة أو لم يسجل

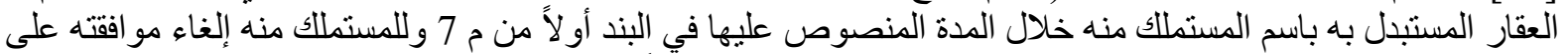

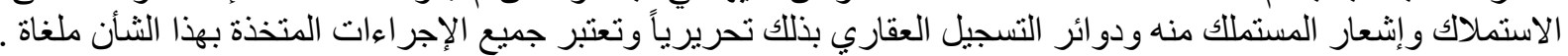

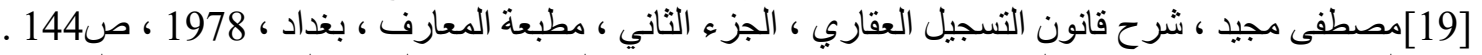

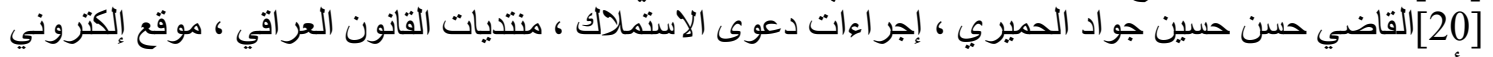
الأنترنت صwww.irag_law.hooxs.com

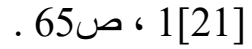
.65. $1[22]$ .865 • 12[23]

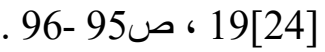

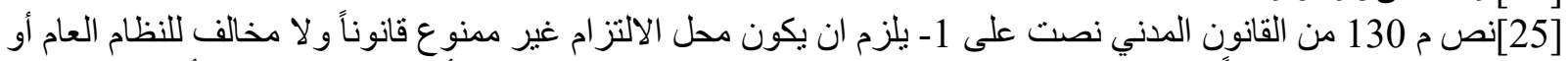

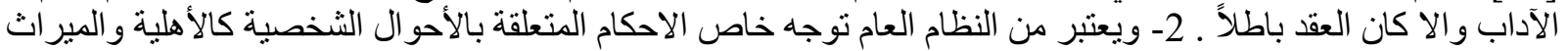

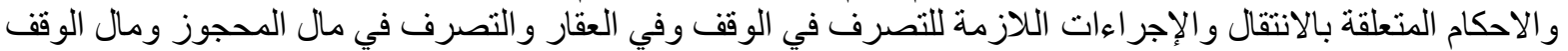

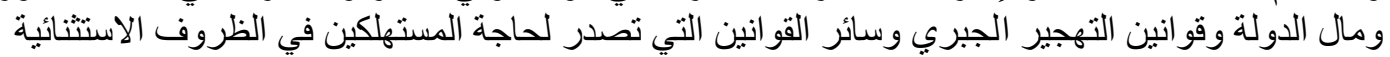

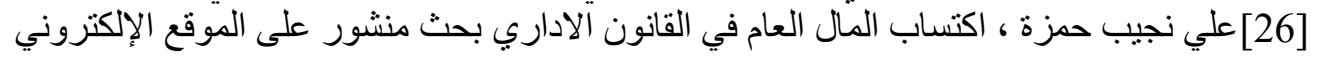
www.unbabylon.edu.iglpublications

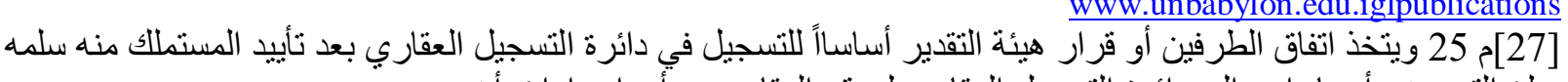

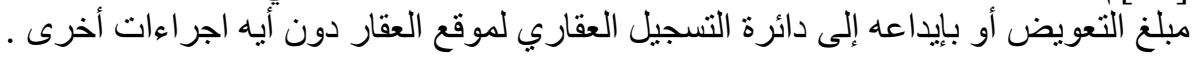

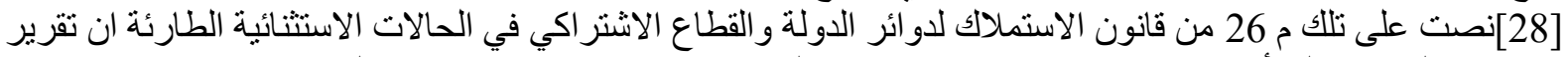

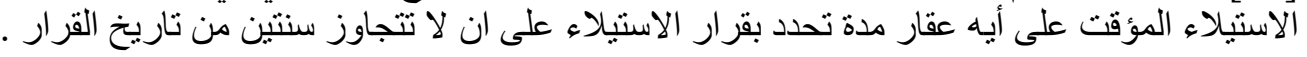
.69. $11[29]$

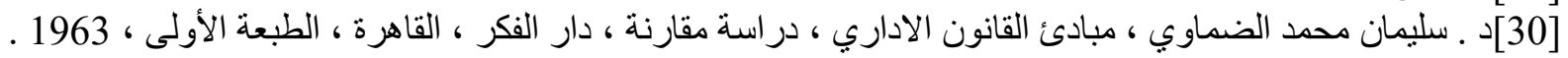

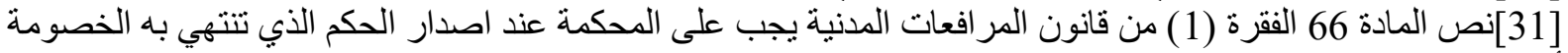

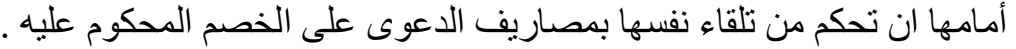

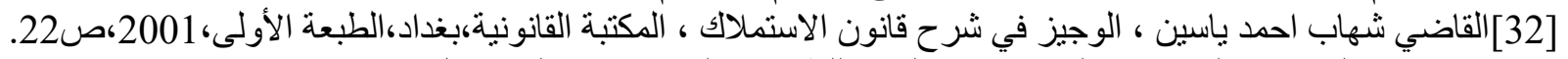

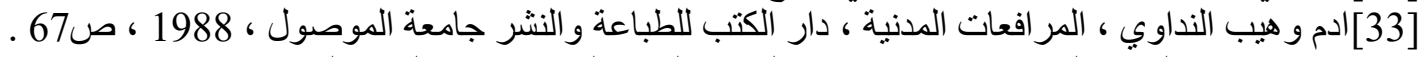

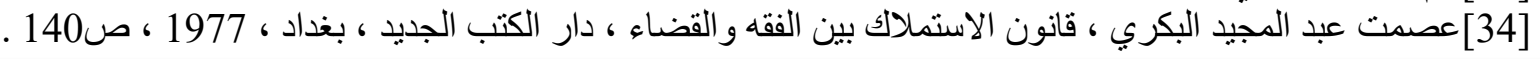


[35] القاضي مدحت المحمود ، شرح قانون المر افعات المدنية رقم 83 لسنة 1969 وتطبيقاته العملية ، الطبعة الأولى ، بغداد ،

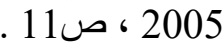

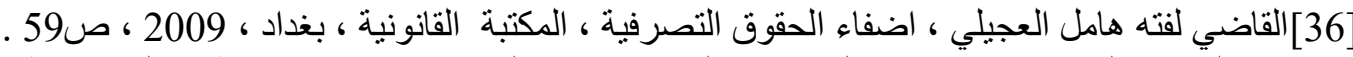
[37] عبد الرحمن العلام ، شرح قانون المر افعات المدنية رقم 83 لسنة 1969 ، ج1 ، مطبعة العاني ، ط3 ، 1996 ، 1963 ، ص32 ، 